\title{
Verzeichnis der Redner
}

$\begin{array}{ll}\text { Alexy S. } 216 & \text { Masing S. } 202 \\ \text { Breuer S. } 430 & \text { Maurer S. } 435 \\ \text { Bryde S. } 165 & \text { Meßerschmidt S. } 179 \\ \text { Bull S. } 196 & \text { Meyer S. 204, } 445 \\ \text { Calliess S. } 160 & \text { Murswiek S. } 168 \\ \text { Classen S. } 450 & \text { Papier S. } 155 \\ \text { Engel S. } 190,440 & \text { Pfersmann S. } 177 \\ \text { Epiney S. } 455 & \text { Püttner S. } 442 \\ \text { Erbguth S. } 465 & \text { Rauschning S. } 447 \\ \text { Götz S. } 447 & \text { Rengeling S. } 453 \\ \text { Grimm S. } 180 & \text { Roellecke S. } 163 \\ \text { Gurlit S. } 199 & \text { Rupp S. } 164,425 \\ \text { Häberle S. } 185 & \text { Sachs S. } 435 \\ \text { Hermes S. } 207 & \text { Schachtschneider S. 205, } 437 \\ \text { Heun S. } 211 & \text { Schefold S. } 198 \\ \text { Hillgruber S. } 174 & \text { Scherzberg S. } 172 \\ \text { Hoffmann-Riem S. } 187 & \text { Schoch S. } 158,426 \\ \text { Höfling S. } 462 & \text { Schuppert S. } 429 \\ \text { Hohmann S. } 194 & \text { Sodan S. } 193 \\ \text { Hufen S. } 166 & \text { Sommermann S. 201, } 452 \\ \text { Iliopoulos-Strangas S. } 197,454 & \text { Spannowsky S. } 443 \\ \text { Isensee S. } 183 & \text { Steiger S. } 158 \\ \text { Kirchhof S. } 161 & \text { Steiner S. } 191 \\ \text { E. Klein S. } 433 & \text { Streinz S. } 457 \\ \text { Th. Koch S. } 189 & \text { Vogel S. } 171 \\ \text { Kunig S. } 214 & \text { Waechter S. } 176 \\ \text { Lange S. } 169 & \text { Wolff S. } 203 \\ \text { Lerche S. } 158 & \text { Zuleeg S. } 449 \\ & \end{array}$


